\title{
The President's Page
}

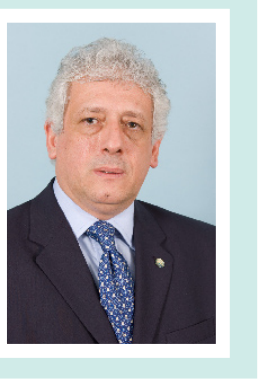

\section{ABC Award - a Golden End to the Year 2008 of the Archives}

\author{
Antonio Carlos Palandri Chagas \\ President of the Brazilian Society of Cardiology - SBC
}

In this first 2009 issue of the Brazilian Archives of Cardiology, I would like to recall the last commemorative event in 2008 of the official journal of our Brazilian Society of Cardiology (SBC). Its $60^{\text {th }}$ anniversary commemoration held in Sao Paulo, had the presence of more than 200 people at the ABC Symposium and the IV ABC Scientific Publication Award.

The ABC Symposium, organized by the newly created Scientific Research Board, whose head is Francisco Rafael M. Laurindo, represented a unique opportunity for discussion. The Editorin-Chief of the Brazilian Archives of Cardiology (Arquivos Brasileiros de Cardiologia), Fernando Bacal, spoke on current issues and the journal perspectives, and the Editor-in-Chief of the Spanish Journal of Cardiology (Revista Española de Cardiología), Fernando Alfonso, presented the example of the publication search due to its excellence and the impact. The Symposium also presented discussion topics such as the impact factor and the new assessment model of the Coordenação de Aperfeiçoamento de Pessoal de Nível Superior (Capes), as well as the presentation of considerations on the current standing of scientific research in Brazil. The discussions were conducted, respectively, by Rogério Meneghini, representing the Scientific Electronic Library Online (SciELO); José R. Lapa e Silva, from Capes; and Eduardo Moacyr Krieger, representing the Brazilian Academy of Sciences. Finally, a general discussion was carried out with the audience and the panel of guests.

The ceremony of the IV ABC Scientific Publication Award was preceded, in addition to the presentation of the Archives, by an international conference on the present and the future of the cardiology scientific publications in the globalized world, also given by the Editor-in-Chief of the Spanish Journal of Cardiology, Fernando Alfonso. In this special award edition that celebrated the sexagenarian SBC journal, the former editors of the journal were also honored.

Subsequently, the ten original articles that won the IV ABC Award were announced, among the 30 finalists. The winners, as well as the entire event, can be checked at the following web address: http://www.arquivosonline.com.br/premion.asp It is important to emphasize the fundamental support of Sanofi-Aventis Pharmaceuticals, which, in the last four years, has made this award possible. We acknowledge the vital role of this company in supporting the Brazilian Archives of Cardiology, to promote, publicize and incentive high-quality cardiovascular research developed in Brazil.

In conclusion, the ceremonies came as a golden end to a year filled with successes for the Archives, especially represented by the journal indexing to Thomson Scientific (former ISI) and by the launching of the Spanish edition of the journal.

We look forward to repeating the excellent results of 2008 in the current year! 